\title{
Chromosomal Duplication
}

National Cancer Institute

\section{Source}

National Cancer Institute. Chromosomal Duplication. NCI Thesaurus. Code C6829.

An irregularity in the number of chromosomes, usually in the form of a gain of genetic

material. $(\mathrm{NCl})$ 